\title{
Histologia e morfometria em cornos uterinos de cadelas nulíparas, multíparas e tratadas com contraceptivos ${ }^{1}$
}

\author{
Cristina Maria Rodrigues Monteiro ${ }^{2 *}$, Silvia Helena Venturoli Perri², Roberto \\ Gameiro de Carvalho ${ }^{2}$ e Marion Burkhardt Koivisto ${ }^{3}$
}

\begin{abstract}
Monteiro C.M.R., Perri S.H.V., Roberto Gameiro de Carvalho R.G. \& Koivisto M.B. 2009. [Histology and morphometry in uterus horns of nulliparous bitches, multiparous ones and bitches treated with contraceptives.] Histologia e morfometria em cornos uterinos de cadelas nulíparas, multíparas e tratadas com contraceptivos. Pesquisa Veterinária Brasileira 29(10):847-851. Departamento de Clínica, Cirurgia e Reprodução Animal, Curso de Medicina Veterinária, Faculdade de Odontologia, Universidade Estadual Paulista, Rua Clóvis Pestana 173, Araçatuba, SP 16065-090, Brazil. E-mail: monteiro@fmva.unesp.br

Histological and morphometric data were obtained from uterus of nulliparous bitches $(n=6)$, multiparous ones $(n=6)$, and bitches treated with contraceptive $(n=6)$. Six samples of uterine horns, cut in average for each group. Measurements of the thickness of the uterine wall, total endometrium, total myometrium, internal myometrium, external myometrium, vascular layer and diameter of normal endometrial glands were not statistically significant between the treated and multiparous bitches, except for the height of the epithelium of normal glands. Measurements of thickness of the uterine wall, total endometrium, total myometrium, myometrium internal diameter and height of the glands of normal glandular epithelium were significant, comparing nulliparous with multiparous bitches and/or treated, except for thickness of the myometrium and vascular outer layer. It can be concluded that (1) the use of contraceptives and successive pregnancies affected uterine structures in its full, (2) the vascular layer and external myometrium were the regions with less variation, (3) morphological changes occurred with the same intensity in the total endometrium and myometrium of treated and multiparous bitches; and (4) the presence of dilated endometrial glands was the difference found in the treated bitches, because they were absent in nulliparous and multiparous ones.
\end{abstract}

INDEX TERMS: Morphometry, uterine horns, endometrium, myometrium, bitches.

RESUMO.- Dados histológicos e morfométricos foram obtidos de útero de cadelas nulíparas $(n=6)$, multíparas $(n=6)$ e de cadelas tratadas com contraceptivo $(n=6)$. Para esse fim foram usadas seis amostras de cornos uterinos, em corte médio, para cada grupo. As mensurações das espessuras da parede uterina, endométrio total, miométrio

\footnotetext{
${ }^{1}$ Recebido em 23 de abril de 2009.

Aceito para publicação em 2 de julho de 2009.

2 Departamento de Apoio, Produção e Saúde Animal, Curso de Medicina Veterinária, Faculdade de Odontologia, Universidade Estadual Paulista (Unesp), Campus de Araçatuba, Rua Clóvis Pestana 793, Araçatuba, SP 16050-680, Brasil.

${ }^{3}$ Departamento de Clínica, Cirurgia e Reprodução Animal, Curso de Medicina Veterinária, Faculdade de Odontologia, Unesp-Araçatuba, SP. *Autor para correspondência: monteiro@fmva.unesp.br
}

total, miométrio interno, miométrio externo, estrato vascular e diâmetro das glândulas endometriais normais não foram estatisticamente significantes entre as cadelas multíparas e tratadas, com exceção para a altura do epitélio de glândulas normais. As mensurações das espessuras da parede uterina, endométrio total, miométrio total, miométrio interno, diâmetro das glândulas normais e altura do epitélio glandular foram significantes, comparando cadelas nulíparas com as multíparas e/ou tratadas, com exceção para as espessuras do miométrio externo e estrato vascular. Diante dos resultados obtidos, pode-se concluir que os dados numéricos confirmam que (1) o uso de anticoncepcionais e sucessivas gestações afetam a estrutura uterina em seu total; (2) o miométrio externo e estrato vascular foram as regiões que menos sofreram alterações compa- 
rando-se os 3 grupos; (3) as variações morfológicas ocorreram com a mesma intensidade no endométrio e miométrio totais para as cadelas tratadas e multíparas, e (4) a presença de glândulas endometriais dilatadas foi o diferencial encontrado nas cadelas tratadas, pois as mesmas estavam ausentes nas multíparas e nulíparas.

TERMOS DE INDEXAÇÃO: Morfometria, cornos uterinos, endométrio, miométrio, cadelas.

\section{INTRODUÇÃO}

Os órgãos genitais de fêmeas domésticas são muito bem retratados no que tange a sua estrutura histológica por Banks (1992), Dellmann (1993), Hafez \& Hafez (2004) e, sobretudo por Augsburger \& Kurzi (2004) que realizaram estudos comparativos entre cadelas da raça beagle nulíparas e multíparas. Já os efeitos do uso de contraceptivos nos órgãos genitais femininos são mais extensos, mas em linhas gerias reportaram a hiperplasia endometrial cística como a principal ocorrência (Cox 1970, Nelson \& Kelly 1976, Solowski \& VanRavenswaay 1979, Kooistra et al. 1997, Perez et al. 1999, Murakoshi et al. 2000, Chatdarong et al. 2005). Outro efeito relacionado ao uso de contraceptivos em cadelas é o surgimento de tumores das glândulas mamárias, masculinização de fetos fêmeas, atraso no parto, diabetes mellitus, acromegalia, supressão do córtex adrenal, alterações de pele e comportamentais (Romagnoli \& Concannon 2003).

Devido à escassez de dados na literatura aliado à importância do assunto, objetivou-se nesta pesquisa, efetuar uma avaliação histológica e morfométrica do útero de cadelas nulíparas, multíparas e tratadas com contraceptivo para se averiguar, comparativamente, as possíveis variações que possam ocorrer.

\section{MATERIAL E MÉTODOS}

Foram utilizados 18 cornos uterinos provenientes de 18 cadelas, a maioria sem raça definida, com idades entre 3 meses a 8 anos, que faziam parte de um projeto de extensão. Os animais foram separados em 3 grupos: 6 cadelas nulíparas, 6 cadelas multíparas e 6 cadelas tratadas com contraceptivo a base de progesterona. Os animais foram submetidos à ovariosalpingohisterectomia no Hospital Veterinário do Curso de Medicina Veterinária, Universidade Estadual Paulista, Campus de Araçatuba. O material coletado após a cirurgia foi fixado em paraformaldeido tamponado a $4 \%$, por 24 horas a 5ㄷ. Posteriormente, fragmentos com $3 \mathrm{~mm}$ de espessura da porção média do corno uterino, foram processados e incluídos em resina paraplast $^{\mathrm{TM}}$. Cortes histológicos de 5 micrometros de espessura foram corados rotineiramente com hematoxilina e eosina e examinados ao microscópio de luz, Olympus CBA. As seguintes mensurações foram efetuadas: (1) espessura total $(\mu \mathrm{m}) \mathrm{da}$ parede uterina (5 campos diferentes em cada amostra histológica); (2) endométrio total (5 campos diferentes em cada amostra histológica), diâmetro das glândulas endometriais (10 glândulas em cada amostra histológica) normais e dilatadas, quando houver e altura dos respectivos epitélios glandulares; e (3) espessura total do miométrio, do miométrio interno, miométrio externo e estrato vascular (5 campos diferentes em cada amos- tra histológica). As mensurações foram obtidas com o programa Image J, que é um programa de análises de imagens para histomorfometria. A estatística constituiu-se de análise de variância e as médias comparadas pelo teste de Duncan e teste t pareado. Utilizou-se o nível de significância de 5\%.

\section{RESULTADOS}

\section{Análise histológica}

Nas cadelas nulíparas o endométrio exibiu pregueamentos longitudinais discretos, superfície revestida por epitélio simples cúbico, lâmina própria de tecido conjuntivo com glândulas tubulares simples ramificadas constituídas por epitélio simples cúbico ou cilíndrico baixo. No miométrio, observaram-se duas camadas discretas de músculo liso, a circular interna e a longitudinal externa, entre elas, o estrato vascular constituído por vasos de grande diâmetro e no perimétrio, tecido conjuntivo frouxo revestido externamente por mesotélio (Fig.1).

As cadelas multíparas apresentaram endométrio com pregueamentos irregulares, revestidos por epitélio sim-

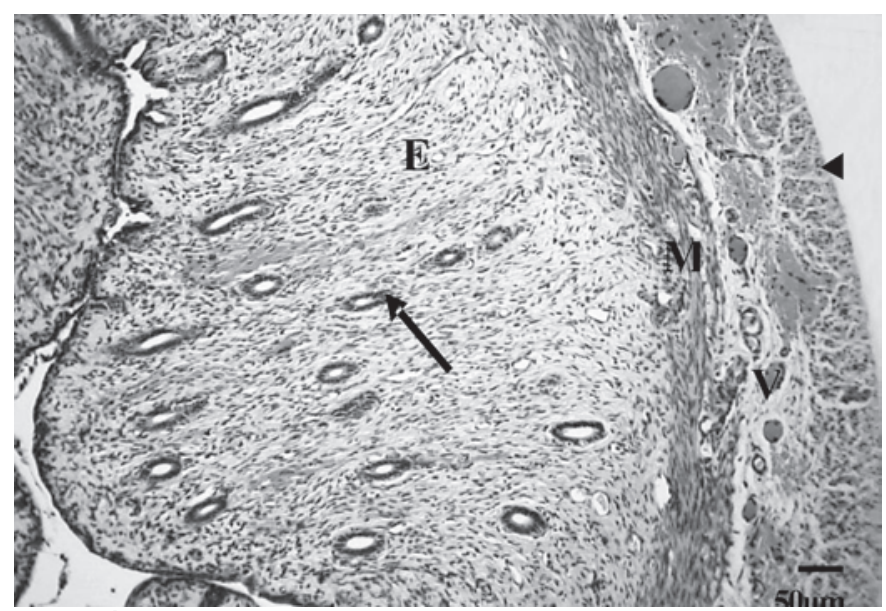

Fig.1. Útero de cadela nulípara. Endométrio (E). Glândula normal (seta). Miométrio (M). Estrato vascular discreto (V). Perimétrio (cabeça de seta). HE, obj.10x. (barra=50 $\mu \mathrm{m}$ )

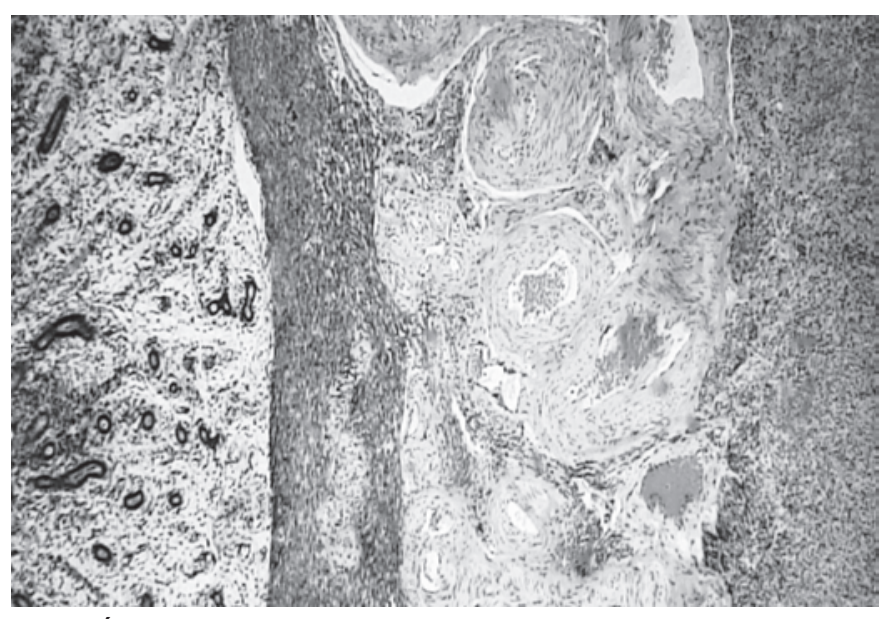

Fig.2. Útero de cadela multípara. Endométrio (E). Miométrio (M). Estrato vascular evidente (V). HE, obj.4x. (barra=100um) 


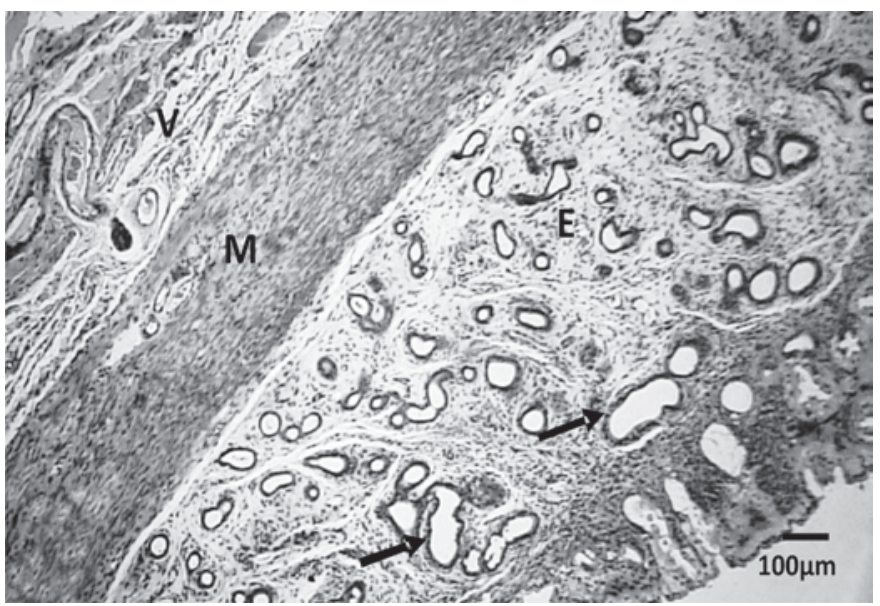

Fig.3. Útero de cadela tratada com contraceptivo. Endométrio (E). Hiperplasia com glândulas dilatadas (setas). Miométrio (M). Estrato vascular (V). HE, obj.4x. (barra $=100 \mu \mathrm{m})$

ples cilíndrico, lâmina própria com glândulas regulares revestidas por epitélio simples cilíndrico. Em uma amostra, observou-se glândula dilatada, revestida por epitélio simples pavimentoso. O miométrio mostrou-se irregular formado por fibras musculares dispostas em várias direções, estrato vascular evidente e perimétrio formado por tecido conjuntivo frouxo revestido externamente por mesotélio (Fig.2).

O endométrio de cadelas tratadas com contraceptivo exibiu pregueamentos irregulares, superfície hiperplásica revestida por epitélio simples cúbico ou cilíndrico com células vacuolizadas, lâmina própria irregular com raras glândulas normais revestidas por epitélio simples cúbico ou cilíndrico baixo e glândulas dilatadas revestidas por epitélio simples cilíndrico. O miométrio mostrou-se, em alguns casos, irregular com estrato vascular evidenciado e o perimétrio formado por tecido conjuntivo frouxo revestido externamente por mesotélio (Fig.3).

\section{Morfometria}

A espessura da parede uterina das cadelas nulíparas foi menor que a espessura das cadelas multíparas e tratadas com contraceptivo, as duas últimas consideradas estatisticamente significantes em relação às nulíparas, porém não significante entre elas. O mesmo resultado foi obtido para a espessura do miométrio, ou seja, não apresentou diferença estatisticamente significante entre as cadelas multíparas e tratadas, mas apresentou entre as duas últimas em relação às cadelas nulíparas. Para a subcamada interna do miométrio houve diferença significante das médias comparando as cadelas nulíparas com as multíparas e tratadas, mas entre as duas últimas não houve diferença significativa. Para a subcamada externa e o estrato vascular não houve diferença estatisticamente significante entre os grupos.

A espessura total do endométrio para as cadelas nulíparas e multíparas não apresentou diferença estatisticamente significante. Entre as cadelas multíparas e tratadas também não houve diferença estatisticamente significante, porém, comparando-se cadelas nulíparas e tratadas houve diferença significativa. A média dos diâmetros das glândulas endometriais mostrou diferença significativa entre as cadelas nulíparas e multíparas, mas não apresentou diferença significante entre as cadelas multíparas e tratadas, entretanto a média dos diâmetros glandulares das tratadas não apresentou diferença significante com as nulíparas. A média das alturas do epitélio glandular mostrou diferença significante entre as nulíparas e multíparas e entre esta última e as tratadas, porém a média entre tratadas e nulíparas não apresentou diferença significante. (Quadro 1).

No Quadro 2, observou-se que as médias do diâmetro entre glândulas endometriais normais e dilatadas das cadelas tratadas apresentaram diferença significante, e as médias da altura do epitélio glandular não mostraram diferença estatisticamente significante.

Quadro 2. Média ( ) e erro padrão da média (EPM) do diâmetro e da altura do epitélio das glândulas normais e dilatadas dos cornos uterinos de cadelas tratadas com contraceptivo

\begin{tabular}{ccc}
\hline Glândulas & Diâmetro $(\mu \mathrm{m})$ & Altura do Epitélio $(\mu \mathrm{m})$ \\
\hline Normais & $37,4 \pm 0,7$ & $9,2 \pm 0,8$ \\
Dilatadas & $89,9 \pm 11,1$ * & $11,1 \pm 1,0$ \\
* $\mathrm{p}<0,05$ & &
\end{tabular}

${ }^{*} p<0,05$.

\section{DISCUSSÃO E CONCLUSÕES}

A parede uterina de cadelas nulíparas caracterizou-se por sua espessura delgada com média de $1272,9 \mu \mathrm{m}$, ao passo que nas cadelas multíparas e nas tratadas com contraceptivos as médias foram $2461,8 \mu \mathrm{m}$ e $2640,9 \mu \mathrm{m}$, respectivamente. Não houve diferença estatisticamente significativa na espessura da parede uterina entre as cadelas multíparas e tratadas, mas como ficou claro, houve

Quadro 1. Média $(\bar{X})$ e erro padrão da média (EPM) das variáveis estudadas nos cornos uterinos de cadelas nulíparas (N) $(n=6)$, multíparas $(M)(n=6)$ e tratadas com contraceptivo $(T)(n=6)$

\begin{tabular}{|c|c|c|c|c|c|c|c|c|}
\hline \multirow[t]{2}{*}{ G } & \multirow{2}{*}{$\begin{array}{l}\text { Parede } \\
\text { uterina }\end{array}$} & \multicolumn{3}{|c|}{ Miométrio $(\mu \mathrm{m})$} & \multirow[b]{2}{*}{ Estrato vascular } & \multicolumn{3}{|c|}{ Endométrio $(\mu \mathrm{m})$} \\
\hline & & Total & Interno & Externo & & Total & Glândulas & Epitélio \\
\hline $\mathrm{N}$ & $1272,9 \pm 159,4 b$ & $721,8 \pm 132,4 \mathrm{~b}$ & $210,7 \pm 46,41 b$ & $236,7 \pm 58,7 a$ & $317,7 \pm 79,7 \mathrm{a}$ & $611,0 \pm 55,9 b$ & $26,3 \pm 1,2 b$ & $6,7 \pm 0,4 b$ \\
\hline
\end{tabular}

Médias seguidas de letras distintas, na coluna, diferem entre si pelo teste de Duncan $(p<0,05)$. 
diferença destas com as nulíparas, confirmado por dados numéricos que sucessivas gestações e o uso de anticoncepcionais afetam a estrutura uterina em seu total. $O$ endométrio das cadelas nulíparas mostrou-se delgado com glândulas e epitélio glandular discretos, miométrio delgado constituído por duas subcamadas, com aproximadamente as mesmas mensurações separadas por um estrato vascular bem evidenciado. Este padrão histológico foi confirmado por Banks (1992), Dellmann (1993) e Hafez \& Hafez (2004) com exceção do epitélio superficial, classificado como simples cilíndrico, sendo este o tipo de epitélio encontrado no grupo de cadelas multíparas. Galabova et al. (2003), entretanto, relataram que o epitélio endometrial nas cadelas varia de simples cúbico no anestro a cilíndrico no diestro, onde alcança altura máxima, sob influência da progesterona.

Nas cadelas multíparas o endométrio estava espessado e irregular com média de $1126,2 \mu \mathrm{m}$, mensuração mais elevada que a do endométrio de cadelas nulíparas, porém esta diferença não foi significativa devido à variabilidade das medidas avaliadas em cada órgão. As glândulas normais apresentaram diâmetro médio e altura de epitélio, estatisticamente significantes quando comparados aos resultados das cadelas nulíparas. O miométrio cuja espessura total de $1321,7 \mu \mathrm{m}$, foi considerada significante em relação à das cadelas nulíparas. As médias das subcamadas foram semelhantes entre si, porém o estrato vascular, caracterizado por vasos dilatados com paredes espessas, apresentou média mais elevada que as subcamadas miometriais. A média da subcamada interna das cadelas multíparas foi estatisticamente significante em relação às cadelas nulíparas, o mesmo não ocorrendo para a subcamada externa e para o estrato vascular, apesar do aumento dessas mensurações. Este aumento na espessura da parede uterina é um fenômeno sugestivo de variações estruturais em decorrência de sucessivas gestações. Augsburger \& Kurzi (2004) relataram em cadelas "beagles" multíparas um aumento de tecido conjuntivo miometrial e presença de vasos sanguíneos com espessamento da túnica média em artérias e da adventícia em veias.

O endométrio de cadelas tratadas com contraceptivo apresentou espessura não significativa em relação ao endométrio das cadelas multíparas, porém significativa quando comparada às cadelas nulíparas. Um caso apresentou alterações características de hiperplasia endometrial cística cujos achados histológicos são semelhantes aos descritos por Bigliardi et al. (2004). Nelson \& Kelly (1976) e Sokolowski \& Van Ravenswaay (1976) concluíram que o uso de contraceptivos induz ao aparecimento de hiperplasia endometrial cística em cadelas, de grau leve com o uso de doses baixas e de grau moderado a severo com o uso de altas dosagens. Nos demais casos foram claramente observados hiperplasia aliada à presença de glândulas dilatadas com diâmetro e altura de epitélio pouco elevado.

As glândulas normais apresentaram diâmetro médio menor, mas não significante em relação às multíparas e nulíparas. Já a altura do epitélio glandular $(9,2 \mu \mathrm{m})$ decresceu em relação ao das multíparas e foi semelhante ao das nulíparas, o que indica um retrocesso nas dimensões dessas estruturas e possibilita afirmar que são variações típicas encontradas em cadelas que receberam contraceptivos.

O miométrio mostrou-se semelhante ao das cadelas multíparas, espesso e irregular corroborando as conclusões de Chatdarong et al. (2005) que encontraram em gatas tratadas com contraceptivo, miométrio significativamente mais espesso. A espessura total do miométrio foi de $1402,7 \mu \mathrm{m}$, para a subcamada interna foi de $521,1 \mu \mathrm{m}$ e para a externa de $343,6 \mu \mathrm{m}$, e o estrato vascular $577,5 \mu \mathrm{m}$, estatisticamente não significantes comparados às cadelas multíparas. Mas do ponto de vista morfométrico, ficou claro que as variações mais evidentes aconteceram no miométrio total e na subcamada interna comparativamente às cadelas nulíparas.

Diante dos resultados obtidos, pode-se concluir que: não houve diferença estatisticamente significativa na espessura da parede uterina entre as cadelas tratadas e multíparas, mas houve diferença destas com as nulíparas, confirmado por dados numéricos que o uso de anticoncepcionais e sucessivas gestações afetam a estrutura uterina em seu total; as demais estruturas analisadas, miométrio total, miométrio interno, miométrio externo, estrato vascular, endométrio total e diâmetro glandular (com exceção para a altura do epitélio glandular) também obtiveram mensurações semelhantes entre cadelas tratadas e multíparas, porém diferentes das nulíparas, com exceções do miométrio externo e estrato vascular, sendo estas, as regiões que menos sofreram alterações; as médias das espessuras do endométrio e miométrio totais foram semelhantes entre si e entre as cadelas tratadas e multíparas, fato sugestivo de que as variações morfológicas ocorreram com a mesma intensidade em ambas as camadas; e a presença de glândulas endometriais dilatadas, foi o diferencial encontrado nas cadelas tratadas, pois as mesmas estavam ausentes nas multíparas e nulíparas.

\section{REFERÊNCIAS}

Augsburger R.H.\& Kurzi M. 2004. Histomorphologic and morphometric evaluation of the uterine horns in nulliparous and multiparous beagles. Am. J. Vet. Res. 65(5):552-558.

Banks W.J. 1992. Histologia Veterinária Aplicada. $2^{\underline{a}}$ ed. Manole, São Paulo. 629p.

Bigliardi E., Parmigiani E., Cavirani S., Luppi A., Bonati L. \& Corradi A. 2004. Ultrasonography and cystic hyperplasia-pyometra complex in the bitch. Reprod. Domest. Anim. 39(3):136-140.

Chatdarong K., Rungsipipat A., Axnér E. \& Forsberg C.L. 2005. Hysterographic appearance and uterine histology at different stages of the reproductive cycle and after progestagen treatment in the domestic cat. Theriogenology 64(1):12-29.

Cox J. 1970. Progestagens in bitches: A review. Small Anim. Pract. 11:759.

Dellmann H.D. 1993. Histologia Veterinária. $2^{\underline{a}}$ ed. Acribia, Zaragoza. $398 p$. 
Galabova G., Egerbacher M., Aurich J. E., Leitner M. \& Walter I. 2003. Morphological changes of the endometrial epithelium in the bitch during metoestrus and anoestrus. Reprod. Domest. Anim. 38(5):415-20.

Hafez ES.E. \& Hafez B. 2004. Reprodução Animal. $7^{\text {ạ }}$ ed. Manole, São Paulo. 513p.

Kooistra H.S., Okkens A.C., Mol J.A., Van Garderen E., Kipensteijn J. \& Rijnberk A. 1997. Lack of association of progestin-induced cystic endometrial hyperplasia with $\mathrm{GH}$ gene expression in the canine uterus. J. Reprod, Fertil. 51(Suppl.):355-361.

Murakoshi M., Tagawz M. \& Ikeda R. 2000. Histopathological studies of subcutaneous implantation of chlormadinone acetate (CMA) for preventing estrus in queens. Tokai J. Exp. Clin. Med. 1(25):7-10.

Nelson L.W. \& Kelly W.A. 1976. Progestogen-related gross and microscopic changes in female Beagles. Vet. Pathol. 13(2):143-56.

Perez J.F., Conley A.J., Dieter J.A., Sanz O.J. \& Lasley B.L. 1999. Studies on the origin of ovarian interstitial tissue and the incidence of endometrial hyperplasia in domestic and feral cats. General Comp. Endocrinol. 116(1):10-20.

Sokolowski J.H. \& VanRavenswaay F. 1976. Effects of melengestrol acetate on reproduction in the Beagle bitch. Am. J. Vet. Res. 8(37):943-945. 